\title{
Editorial: Special Issue in Honour of Dr. Steven Renzetti
}

\author{
Diane P. Dupont \\ Department of Economics \\ Brock University, Canada \\ ddupont@brocku.ca
}

Published 26 April 2019

\section{Introduction}

Over the last few years, the interaction between water quantity and water quality has come to the attention of policymakers in the face of climate change concerns. Predicted increases in the average earth temperature will affect the hydrological cycle (IPCC 2018). Specifically, the literature warns about increasing variability and unpredictability around precipitation (Willner et al. 2018). This means that most places on earth can expect to experience too much water (flooding), too little water (shortages), and changes in water quality. The myriad roles that water plays in both economic and social well-being are now being recognized at a global level with two of the UN Sustainable Goals identifying water specifically and many of the other 15 goals relying upon the availability of good quality water for support (UN Sustainable Goals Development, 2017). Concern for water has not always the case, particularly in Canada that has been blessed with abundant sources of potable water, as well as access to three oceans (Natural Resources Canada, The Atlas of Canada, 2017). In large measure, Canadian citizens, in particular, but also those in other developed countries have not recognized the important contributions made by water, nor have they fully paid for them. To some extent, this state of affairs has arisen due to challenges faced in identifying and measuring water's myriad contributions. Even though the contribution of water to the Canadian economy was the subject of a Federal Inquiry in 1985, the economist charged with undertaking the analysis found the data to be limited and, in many cases not 
measured (Muller 1985). A report undertaken by Steven Renzetti with two colleagues to update the Muller findings reported that the situation, while still problematic, was at least more prevalent in the public eye and of greater interest to policymakers (Renzetti et al. 2011). It was this recognition of the key role of water as an asset in an economy to be valued that was the main goal and contribution of Steven Renzetti, the economist whose work is being honoured by five papers in this volume.

A number of reasons are at play that challenge our ability to measure water's important contributions to an economy. These include the means by which water service providers charge for water and the fact that many of water's services are not provided directly by markets, so values are not revealed in consumer choices. Inadequate pricing of services supplied by utilities inevitably has led to an absence of a conservation ethic by consumers and misallocation of resources. Steven Renzetti began his career with a doctoral thesis that examined the welfare implications of inefficient pricing of water in a water-abundant location (Renzetti 1992a, 1999). Even under those circumstances, welfare improvements could be made through proper marginal cost pricing that would provide both short-term and long-term incentives to use a country's water assets appropriately. Along with his subsequent work on industrial water demands and permit pricing for selfsupplied water users, as well as his work on ownership and performance, his widely cited water pricing work led to his recognition as Canada's leading water economist (Renzetti 1992b, 1993; Renzetti and Dupont 2003). He was sought by governments and non-profit organizations to provide expert opinion on water pricing and policies and he served on the International Joint Commission's Lake Ontario St Lawrence Study Board, on the Council of Canadian Academies' Expert Panel on Sustainable Groundwater, on an Expert Advisory Panel to the National Roundtable on Environment and Economy, and as the first Scientific Director of the Water Economics, Policy, and Governance Network. This network was supported by a Social Sciences and Humanities Research Council Partnership Grant that brought together a multidisciplinary and international team of academic researchers, students, and institutional partners to enhance understanding of, and provide practical solutions for, pressing issues related to water availability and water quality. Since its beginning in 2012, the network created by Steven has supported over 20 projects employing more than 30 researchers, involving more than 40 government/industry partners, and providing mentoring experiences for more than 60 undergraduate and/or graduate students. The projects supported are wide ranging in scope: from examining the economic costs of wildfires upon water quality to developing models to better forecast water demands to promote sustainable management to evaluating models of Indigenous 
water governance. The papers in this special edition reflect this broad range of interests in water. It is fitting that two of these papers (2.3 and 2.4) feature the works of several students who gained valuable experience while participating in the network.

\section{Overview of the Papers}

This special issue includes five papers that illustrate the development and, specifically, the broadening focus, of the field of water economics over the last few decades. The papers include: one that focuses upon the assessment of water pricing rate structures for achieving both economic and social goals and a second that calculates the welfare effects a specific set of residential pricing structures. While these papers look particularly at water in its quantity aspect, the three remaining papers delve into water's quality attributes and how values may be obtained for non-market services provided by water. Many of the papers illustrate the importance of having appropriate econometric techniques to expand our analytical understanding of the role that water plays in an economy. While many of the papers use North America as a geographical focus for a case study, a further paper gives us a view into water issues in South Africa. These papers share a common theme of the need to understand institutions and contexts surrounding water problems and that many problems require an interdisciplinary lens of inquiry. Finally, the lessons from these papers are relevant to current policy and governance challenges (including environmental sustainability), particularly, as they involve water demands, water pricing, water valuation, and payments for ecosystems services.

\section{1. "Metrics and methods for comparing water utility rate structures" by Honey-Rosés and Pareja}

This paper looks at the broad issue of how to assess and compare rate structures used by water utility suppliers. Given the nature of water supply an optimal rate structure involves more than a single price per unit. It has long been suggested that water prices comprise two parts: the first being a fixed amount intended to assist in paying for the capital infrastructure and the second being a price related to volume consumed to assist in paying the short-term opportunity costs associated with meeting increasing demands (Renzetti 1992a). The paper notes a key challenge faced by a regulator or policymaker wishing to benchmark water utility performance. Namely, data are often not available to measure many of the components that would ideally be used in designing an optimal rate structure. A practical 
alternative as suggested by the authors is a benchmarking comparison of utility performance using data that is publicly or easily available.

In order to operationalize their benchmarking approach, the authors review a number of different metrics currently in use and evaluate them through the lens of their ability to achieve four different objectives: efficiency, conservation, equity, and cost recovery. They provide a very useful summary of their findings that highlights both strengths and limitations of the different metrics. A particularly useful outcome (and challenge for putting benchmarking into practice) is the finding that precise definitions for metrics are not universally employed. Using their analytical framework as a basis for a comparison across the four objectives, the paper illustrates the approach both visually and descriptively using data from five municipalities in the province of British Columbia, Canada that differ by population characteristics. Perhaps, the most interesting of their findings is that two pairs of the five communities have very different rate structures but they converge in terms of the total charge assessed at a level of consumption of $25 \mathrm{~m}^{3}$ per month. (For example, one pair is Vancouver that uses a flat rate and West Vancouver that uses an increasing block rate but they both charge $\$ 50$ for this volume of water consumed while the second pair is Nanaimo using an increasing block rate and Abbotsford using a constant unit charge both ending up charging just under $\$ 30$ for the same volume.). The authors speculate that this may arise from a type of convergence to the metric used by Environment Canada to compare water prices charged by municipalities across Canada and end their article by suggesting alternatives that may more broadly encompass the four objectives rather than focus upon a single goal.

\section{2. "Can allocation-based water rates promote conservation and increase welfare? A California case study" by Baerenklau and Pérez-Urdiales}

Water pricing structures that both provide signals to consumers to conserve on water use and reflect the opportunity costs of resources used in providing water has been a subject of great interest for more than three decades (Renzetti 1992; Renzetti 1999). Using household level data from Southern California, a state that has had many years of water scarcity, this paper looks at the potential impacts and welfare implications of allocation-based water prices (rates). While increasing block rate structures have been advocated for many years to encourage water conservation, allocation-based rates have seen less attention. In part, this is because they are more complex to put into practice since the block sizes depend upon household characteristics, as well as utility judgements about the definition of 
efficient use and other norms relating to consumption. The key challenge for analysis is that water prices increase as consumption increases but in a non-linear fashion. This is also a complication for empirical investigation.

This paper presents and estimates a model of water demand and welfare evaluation in the presence of non-linear pricing. The authors estimate a two-error discrete continuous choice model that allows the researcher to account for potential endogeneity of prices (due to the non-linearity noted above). The key to the analysis is estimation of parameters of the underlying utility function which are then used to calculate equivalent variation measures of welfare. An interesting innovation of this paper is the inclusion of persistent but unobserved household specific heterogeneity that is recognized as driving differential changes in water demand. Welfare estimates from the allocation-based rate model are compared with those obtained from a more traditional increasing block rate model, as well as a uniform rate model and a pro-environment allocation-based rate model that reduces indoor consumption levels by more than $1 / 2$ (leading to smaller block sizes). The paper's results show that the welfare effects of alternative block rate pricing (uniform block sizes) are positive and similar to the individual block rates, and that both are better (on average) than uniform rates. These gains in welfare arise even though water consumption decreases. However, the authors caution that predicted welfare gains are aggregate and that some lowincome individual households, due to their preferences, might actually be worse off with the introduction of the alternative rate structures. The presence of regressivity is a challenge to the adoption of this type of rate structure by government regulators.

\section{3. "Reliability of drinking water: Risk perceptions and economic value" by Appiah et al.}

Water has many attributes that are valued by households. While the two previous papers focus upon the consumption levels, this paper focuses upon the reliability of water supplied to households by water service providers. Households expect to turn on their water taps and have a steady stream of good quality water that is always available without disruption. However, this does not always happen. In particular, some municipalities are facing potential disruptions to water supply from an unexpected source: an increase in the frequency and severity of forest fires that are the major sources of water supply (Emelko et al. 2011; Denver Water 2013). Source water protection has become an important feature in ensuring that municipalities are able to deliver on high quality water. The value of the provision of reliable drinking water to households is of interest to water service providers and water regulators 
alike. However, the definition of reliable water is multidimensional. In particular, it is important to know whether households are willing to pay more to reduce the likelihood of longer-term water outages or those that involve a "boil water" advisory than shorter-term outages, since the latter is less costly for households to mitigate.

This paper describes the results of a non-market valuation survey undertaken in the province of Alberta, Canada in 2015, a province that has experienced an increase in the number and extent of forest fires over the last 50 years (Hanes et al., 2019). The preference revealing question is a referendum style (yes, no) format which reduces the cognitive burden on respondents (Carson and Groves, 2007). The paper employs both objective absolute risk reduction attributes (reduction in the probability of water outage) and relative risk reduction estimates that are subjectively defined by the respondents. This innovative use of perceived individual risks as the baseline values for the description of the status quo scenario provides benefits in terms of greater salience to respondents. However, it introduces an econometric challenge in that there is a potential endogeneity in the explanatory variables. The paper deals with this econometric challenge through the use of a control function approach. It also employs spike models to allow for the inclusion of respondents in the estimation of willingness-to-pay even though they have expressed a subjective belief of no future risks of water outages. The paper finds that households are willing to pay more per year to reduce the joint risks of a number of aspects of unreliable water (short-term outages, longer-term outages and "boil water" advisories) and that these values are quite substantial in relation to typical water bills. These estimates are compared to estimates of infrastructure costs and are found to be of similar magnitude, suggesting that households in Alberta are willing to pay in the ballpark for infrastructure improvements to reduce their risks of unreliable water.

\subsection{Floods and water service disruptions: Eliciting willingness-to-pay for public utility pricing and infrastructure decisions" by Price et al.}

This is a timely contribution to the literature on the values placed by households on water services provided to communities by public water and wastewater utilities. The paper highlights the importance of the role of infrastructure and management challenges that face utilities, where many of the current problems have been exacerbated through years of inefficient pricing of water and wastewater services (Renzetti 2009; Ragan et al. 2017). This has led to an underinvestment in appropriate infrastructure. Recently, there has been an increasing interest in identifying the importance of these services to citizens and, more 
importantly, quantifying the willingness of citizens to pay for these services (American Water Works Association, 2015). In many cases, markets do not exist for these services since they are typically provided by a sole supplier. In order to elicit preference and determine citizen values, researchers have employed nonmarket techniques. In particular, the paper describes a method to obtain values that citizens hold to obtain services that would both avoid supply disruptions and reduce the risks of too much water through flooding. This is a challenge faced by many urban water/wastewater service providers since many places on earth experience both problems on an annual cycle that may become more frequent due to climate change.

The authors employ a choice experiments survey methodology (Carson and Groves, 2007) to elicit preferences from a random sample of 1600 online survey respondents (representative of the Canadian population) in 2016. Respondents provide background experiences with both supply disruptions and urban flooding. The survey also asks a series of questions designed to elicit subjective perceived risk levels (in the form of annual probabilities) for these types of events. In the choice experiments, respondents vote on a choice of either staying with status quo or paying money for a reduction in the risks of these two events. In addition, the valuation questions explore the extent to which public preferences exist for reducing risks through green infrastructure versus traditional engineering or grey infrastructure. Willingness-to-pay values are obtained through employing a random-effects probit model to explain choices. Results show that Canadian households hold slightly higher values for reductions in flood risks, however, there is heterogeneity across Canada in terms of expressed willingness-to-pay for reducing the risks of supply disruption and flooding events with rural residents and areas with higher than average house prices expressing higher values. Interestingly, green infrastructure approaches are preferred only in the case of providing solutions to water supply disruption. Finally, the authors note that surcharges on water bills designed to mitigate both these risks could be a way forward for municipalities struggling to deal with infrastructure challenges.

\section{5. "Lay knowledge of ecosystem services in rural eastern cape province, South Africa: Implications for intervention program planning" by Murata et al.}

In this paper, the focus on water broadens even further to put it into the context of the payments for ecosystems services literature. As well, the case study moves beyond the North American urban geographical limitations to small villages in the 
northern Eastern Cape region of South Africa, a water-stressed country. A concern with water within the context of ecosystem services is a natural progression for examining the value of water as an asset to an economy (Boyd and Banzhaf 2007). The paper provides insights into a possible gap in understanding between "scientific" notions of ecosystem services and "lay" notions of the services received by a community from natural assets. This is an important point to understand since the valuation of non-market goods/services such as those provided by water is done by the lay population as a means of identifying public preferences for environmental programs (Costanza 2008).

In recognition of the specific needs and complexity of the issues being studied, the authors employ a mixed methods survey approach that collects both quantitative and qualitative data. The approach is similar to that of the other two valuation papers in that respondents are queried as to their subjective beliefs and understandings, as opposed to having objective ones imposed upon them. Respondents are directed to rank order ecosystem services with provisioning services (water supply) being first ranked. Although they are least familiar with regulatory and supporting services when presented to them by those names, respondents do identify water pollution as the most challenging of ecological problems they have personally experienced. The important lesson here is the potential gap between the understanding and hence, values, expressed by a community for the services of water within the ecosystem and the naming conventions used by planners and policymakers that aim to introduce payments for ecosystem services programs. This gap needs to be bridged if we are to obtain values needed for decision-making.

\section{Lessons and Challenges for Water Policy}

Each of these papers provides a lesson and poses a challenge for either water utilities or the regulatory institutions that oversee them. The papers by HoneyRosés and Pareja as well as Baerenklau and Urdiales challenge water utilities to develop water rate structures that are not only more transparent and open in how services are priced but also take advantage of the prevalence of "big data" to tailor pricing structures that can be more finely tuned to achieve a number of goals. The lesson from the first paper is that rate structures have many components but that relevant information both to consumers and municipal decision-makers can be illustrated through the use of graphs. These visualizations also facilitate comparisons of how water utilities might be able to make tradeoffs across a number of different goals that have been assigned to them. If the concern is regressive pricing that disproportionately harms low-income, low-water users, then households can 
be presented with lifeline volumes offered at lower rates. These household are identified through the use of data mining and analysis. Allocation-based block rates can be structured to accommodate this concern. Since many utilities are concerned with both water and wastewater services together, on the opposite end of pricing differentials to various users is the question of whether high-volume, high-income users can be charged more to reflect a greater use of water's services. For example, results from the Price et al. paper show households in higher-priced homes are willing to pay more to reduce risks of urban flooding related damages. An allocation-based rates structure could be modified with a surcharge system to reflect the broader set of services from water.

There is a common lesson from the three survey-based papers (Price et al., Appiah et al., and Murata et al.). Incorporation of lived experiences and expressed subjective views on the nature of the status quo against which a valuation program is being compared can enrich and improve non-market valuation approaches for obtaining stated preferences for non-marketed goods and services. While this leads to a potential endogeneity problem, new econometric methods are being developed that allow the analyst to embrace the heterogeneity in preferences. This can only lead to more precise estimates of willingness-to-pay that can be used to identify how best to use scarce water assets (Renzetti et al. 2011). The challenge is that we need to move beyond thinking of water as having one or even two (e.g., quantity and quality) attributes. Water provides many services that are interlinked. To truly understand its roles and contributions to both economic and social well-being, teams of researchers with broad perspectives and individual technical strengths must unite. This will more easily facilitate the incorporation of the specific context in which water is being considered and also bring multidisciplinary perspectives to bear on how the world uses its most precious asset, water. In so doing, we will avoid having water run through our fingers, thereby reducing the benefits to the world's citizens.

\section{References}

Boyd, J and S Banzhaf (2007). What are ecosystem services? The need for standardized environmental accounting units. Ecological Economics, 63, 616-626.

Costanza, R (2008). Ecosystem services: Multiple classification systems are needed (Letter to the Editor). Biological Conservation, 141, 350-352.

Denver Water (2013). From Forests to Faucets: U.S. Forest Service and Denver Water Watershed Management Partnership. Available at: http://www.denverwater.org/ supplyplanning/watersupply/partnershipUSFS (accessed April 1, 2019).

Emelko, MB, Silins, U, Bladon, KD and Stone, M (2011). Implications of land disturbance on drinking water treatability in a changing climate: Demonstrating the need for 
“source water supply and protection" strategies. Water Research, 45(2), 46-472, http://doi.org/10.1016/j.watres.2010.08.051.

Hanes, C, Wang, X, Jain, P, Parisien, M-A, Little, J and Flannigan, M (2018). Fire-regime changes in Canada over the last half century. Can. J. For. Res., 49, 256-269.

Intergovernmental Panel on Climate Change (IPCC) (2018). Global Warming of $1.5^{\circ} \mathrm{C}$. Summary for Policymakers. October 6, 2018. http://report.ipcc.ch/sr15/pdf/ sr15_spm_final.pdf (accessed March 15, 2019).

Muller, RA (1985). The Socioeconomic Value of Water in Canada. Research paper number 5 written for the Inquiry on Federal Water Policy (the Pearse Inquiry).

Natural Resources Canada, The Atlas of Canada (2017). Water, https://www.nrcan.gc. ca/earth-sciences/geography/atlas-canada/selected-thematic-maps/16888 (accessed March 9, 2019).

Ragan, CR, Cappe, M, Hodgson, G, Beale, E, Dahlby, B, Lipsey, R, Boothe, P, Drummond, D, Olewiler, N, Elgie, S and St-Hilaire, F (2017). Only the Pipes Should Be Hidden: Best Practices for Pricing and Improving Municipal Water and Wastewater Services, https://ecofiscal.ca/wp-content/uploads/2017/09/EcofiscalCommission-Report-Only-the-Pipes-Should-be-Hidden-FINAL-Sept-26-2017.pdf [23 March 2018].

Renzetti, S (1992a). Evaluating the welfare effects of reforming municipal water prices. Journal of Environmental Economics and Management, 22(2), 147-163.

Renzetti, S (1992b). Estimating the structure of industrial water demands: The case of canadian manufacturing. Land Economics, 68(4), 396-404.

Renzetti, S (1993). Examining the differences in self-and publicly supplied firms' water demands. Land Economics, 69(2), 181-188.

Renzetti, S (1999). Municipal water supply and sewage treatment: Costs, prices, and distortions. Canadian Journal of Economics, 32(3), 688-704.

Renzetti, S (2009). Wave of the future: The Case for Smarter Water Pricing. C.D. Howe Institute Commentary No. 281, https://www.cdhowe.org/sites/default/files/attachments/researchpapers/mixed//commentary281.pdf (accessed April 16, 2018).

Renzetti, S and D Dupont (2003). Ownership and Performance of Water Utilities. Reprinted in Chenoweth, J and Bird, J (eds.) (2005). The Business of Water Supply and Sustainable Development, Greenleaf Publishing, 99-110.

Renzetti, S, D Dupont and C Wood (2011). Running Through our Fingers. How Canada Fails to Capture the Full Value of its Top Asset. Written for the Blue Economy Initiative sponsored by the Royal Bank of Canada, the Canadian Water Network, and the Water \& Duncan Gordon Foundation, 31 pp., http://cwn-rce.ca/report/runningthrough-our-fingers-how-canada-fails-to-capture-the-value-of-its-top-asset/.

United Nations Sustainable Goals Development (2017). https://www.un.org/sustainabledevelopment/sustainable-development-goals/ (accessed April 6, 2019).

Willner, S, C Otto and A Levermann (2018). Global economic response to river floods. Nature Climate Change Letter, https://doi.org/10.1038/s41558-018-0173-2. 